\title{
Neonatal outcomes among twins following assisted reproductive technology: an Australian population-based retrospective cohort study
}

\author{
Alex Y. Wang ${ }^{1 *}$ (D, Nadom Safi ${ }^{1}$, Fathalla Ali ${ }^{2}$, Kei Lui ${ }^{2}$, Zhuoyang Li ${ }^{1}$, Mark P. Umstad ${ }^{3}$ and Elizabeth A. Sullivan ${ }^{1}$
}

\begin{abstract}
Background: While their incidence is on the rise, twin pregnancies are associated with risks to the mothers and their babies. This study aims to investigate the likelihood of adverse neonatal outcomes of twins following assisted reproductive technology (ART) compared to non-ART twins.

Methods: A retrospective population study using the Australian National Perinatal Data Collections (NPDC) which included 19,662 twins of $\geq 20$ weeks gestational age or $\geq 400 \mathrm{~g}$ birthweight in Australia. Maternal outcomes and neonatal outcomes (preterm birth, low birth weight, resuscitation and neonatal death) were compared. Generalized Estimating Equations were used to assess the likelihood of any neonatal outcomes, with adjusted odds ratio (AOR) and $95 \%$ confidence intervals (Cl) presented. Weinberg's differential rule was used to estimate monozygotic twin rate.

Results: ART mothers were 3.3 years older than non-ART mothers. The rates of pregnancy-induced hypertension and gestational diabetes were significantly higher for ART mothers than non-ART mothers $(12.2 \%$ vs. $8.4 \%, p<0.01)$ and $(9.7 \%$ vs. $7.5 \%, p<0.01$ ) respectively. The incidence of monozygotic twins was $2.0 \%$ for ART twins and $1.1 \%$ for non-ART twins. Compared with non-ART twins, ART twins had higher rates of preterm birth (AOR 1.13, 95\% Cl: 1.05-1.22), low birth weight (AOR 1.13, 95\% Cl: 1.05-1.22), and resuscitation (AOR 1.26, 95\% Cl: 1.17-1.36). Liveborn ART twins had 28\% (AOR $1.28,95 \% \mathrm{Cl} 1.09-1.50$ ) increased odds of having any adverse neonatal outcome compared to liveborn non-ART twins, especially for opposite-sex ART twins (AOR 1.42, 95\% Cl 1.11-1.82).
\end{abstract}

Conclusion: As ART twins had higher rates of adverse outcome, special prenatal care is recommended. Couples accessing ART should be fully informed of the risk of adverse outcome of twin pregnancies.

Keywords: Assisted reproductive technology, Twins, Neonatal death, Premature birth, Stillbirth

\section{Background}

The rate of twin birth has been increased in the past four decades. In the United States, the twin birth rate has increased by $76 \%$; from $1.9 \%$ in 1980 to $3.3 \%$ in 2009 [1]. In Australia, the rate of multiple deliveries has risen by $15 \%$ from $1.3 \%$ in 1992 to $1.5 \%$ in 2012 [2, 3]. One of the main reasons behind twining rate increase is the introduction of assisted reproductive technology (ART)

\footnotetext{
* Correspondence: Alex.Wang@uts.edu.au

${ }^{1}$ Faculty of Health, Australian Centre of Public and Population Health Research, University of Technology Sydney, PO Box 123 Broadway, Ultimo, NSW 2007, Australia

Full list of author information is available at the end of the article
}

[4]. The rate of twin birth is high among ART conceived children representing $43 \%$ in the US [5] and 6.8\% in Australia and New Zealand [6].

Irrespective of the method of conception, twin pregnancies have a greater risk of maternal and neonatal complications compared with singleton pregnancies [7]. When the literature is limited to twins, it is inconsistent with some studies reporting comparable maternal and neonatal outcomes between ART and non-ART twin births [8] while the others have found higher rates of maternal and neonatal complications among ART twin births [4, 9]. There is a lack of national population-based studies in Australia comparing ART and non-ART twins. The aim of

(c) The Author(s). 2018 Open Access This article is distributed under the terms of the Creative Commons Attribution 4.0 International License (http://creativecommons.org/licenses/by/4.0/), which permits unrestricted use, distribution, and 
this study is to investigate the association of ART on the neonatal outcomes among twins in Australia.

\section{Methods}

A national population-based retrospective cohort design was used. The data source of this study is the Australian National Perinatal Data Collection (NPDC) from 2007 to 2011. The NPDC includes information on mothers and babies of all live births and stillbirths of at least 20 weeks gestation or at least $400 \mathrm{~g}$ birthweight [10]. Data on whether the pregnancy resulted from ART were available for five out of the eight states and territories in Australia (Victoria, Queensland, Western Australia, Tasmania and the Australian Capital Territory) and were included in this study. These five states and territories represented approximately $60 \%$ of all births in Australia, with data validation conducted at both state and national levels [10]. The study population included 9831 sets of twin deliveries, with 4580 (23.3\%) ART twins and 15,082 (76.7\%) non-ART twins.

Maternal characteristics included maternal age at delivery, pre-pregnancy body mass index (BMI), parity, smoking during pregnancy, socioeconomic status, the Indigenous status of the mother, and admitted patient elected accommodation status (public/private). Pre-existing maternal conditions included pre-existing hypertension, and pre-existing diabetes. Pregnancy complications included antepartum haemorrhage, pregnancy-induced hypertension, and gestational diabetes. In NPDU, pregnancy-induced hypertension included both gestational hypertension, and pre-eclampsia [10]. Gestational hypertension is the blood pressure exceeding 140/90 mmHg during pregnancy (after 20 weeks' gestation) on two readings at least, of more than six hours apart without pre-existing hypertension [11]. Preeclampsia is defined as the presence of hypertension accompanied by proteinuria, utero-placental or organ dysfunctions [11]. Gestational diabetes is the condition where diabetes is first diagnosed during pregnancy and may disappear after giving birth but considered as a risk factor for diabetes occurring in the future [10].

Outcomes at birth included delivery method, preterm birth (gestational age $<37$ weeks), stillbirth, low birthweight (birthweight $<2500 \mathrm{~g}$ ), Apgar score at $5 \mathrm{~min}$, resuscitation at birth, admission to neonatal intensive care unit or special care nursery (NICU/SCN), length of infant stay in hospital in completed day and neonatal death (within 28 days of birth). Among liveborn twins, a combined measure 'any adverse neonatal outcome' was created if a birth was preterm, low birthweight, Apgar score at $5 \mathrm{~min}<7$, required resuscitation, admitted to NICU/SCN or neonatal death. Neonatal death is defined as the death of a live born baby within 28 days of birth [10].

Maternal characteristics, pre-existing maternal conditions, pregnancy complications and neonatal outcomes were compared between ART and non-ART twins. Chi-squared test for categorical variables and Student's t-test for continuous variables were used for the comparison. Generalized Estimating Equations was used to assess the likelihood of 'any adverse neonatal outcome' following ART treatment, with odds ratio, adjusted odds ratio (AOR) (adjusted for maternal age, parity, Indigenous status of mother, pre-pregnancy BMI, and smoking during pregnancy) and 95\% confidence intervals (CI) presented. Due to high proportion of missing data BMI and smoking during pregnancy, a sensitivity analysis was conducted by excluding smoking or BMI in the adjustment. Weinberg's differential rule was used to estimate monozygotic twin rate [12]. Data were analysed using Statistical Package for Social Sciences (SPSS) software, version 22 (SPSS, Inc., Chicago, IL, USA).

\section{Results}

Table 1 shows maternal demographic characteristics pre-existing conditions and pregnancy complications of ART and non-ART groups. ART mothers were 3.3 years older than non-ART mothers. Compared to non-ART mothers, higher proportions of ART mothers were primiparous, non-smoking, with normal BMI and with private health insurance. One in four ART mothers was from the least $20 \%$ disadvantaged group compared to < $20 \%$ of non-ART mothers (Table 1 ).

Antepartum hemorrhage rate was higher for ART mothers than for non-ART mothers $(5.7 \%$ vs. $4.5 \%, p=$ $0.02)$. The rates of pregnancy-induced hypertension and gestational diabetes were also higher for ART mothers than for non-ART mothers $(12.2 \%$ vs. $8.4 \%, p<0.01)$ and $(9.7 \%$ vs. $7.5 \%, \mathrm{p}<0.01)$ respectively (Table 1$)$.

Table 2 shows the birth outcomes of ART and non-ART twins. More than $60 \%$ of ART twins were born by no labour caesarean section, significantly higher than non-ART twins (46.7\%). ART twins had a significantly lower stillbirth rate than non-ART twins $(1.4 \%$ vs. $2.3 \%$, $p<0.01$ ) (Table 2).

Table 3 shows the monozygotic and dizygotic rate among ART and non-ART twins. Of twins where sex is available for both babies, same-sex twins made up 55.2\% of ART twins compared to $71.4 \%$ non-ART twins. According to Weinberg's differential rule, there were 478 monozygotic ART twins and 6456 monozygotic non-ART twins. This represents a monozygotic twin rate of $2.0 \%$ for ART births and 1.1\% for non-ART births (Table 3).

Table 4 shows the neonatal outcomes of liveborn ART and non-ART twins. Liveborn ART twins had increased odds of low Apgar score at 5 min $(<7)$, preterm birth, low birthweight, requiring resuscitation, and neonatal death than liveborn non-ART twins. Any adverse neonatal outcome was present for $89.0 \%$ of liveborn non-ART twins compared to $95.3 \%$ of liveborn ART 
Table 1 Demographics, pre-existing conditions and pregnancy complications of mothers of ART and non-ART twin sets, Australia, 2007-2011

\begin{tabular}{|c|c|c|c|c|c|}
\hline & \multicolumn{2}{|c|}{ Non-ART mothers $(n=7541)$} & \multicolumn{2}{|c|}{ ART mothers $(n=2290)$} & \multirow{2}{*}{$\begin{array}{l}P \text { value (chi- } \\
\text { squared test) }\end{array}$} \\
\hline & No. & $\%$ & No. & $\%$ & \\
\hline \multicolumn{6}{|l|}{ Maternal age, years } \\
\hline Mean \pm SD & $30.6 \pm 5.4$ & & $33.9 \pm 4.6$ & & $<0.01^{*}$ \\
\hline$<30$ & 3151 & 41.8 & 380 & 16.6 & \multirow[t]{5}{*}{$<0.01$} \\
\hline $30-34$ & 2451 & 32.5 & 874 & 38.2 & \\
\hline $35-39$ & 1678 & 22.3 & 795 & 34.7 & \\
\hline $40-44$ & 253 & 3.4 & 184 & 8.0 & \\
\hline$\geq 45$ & 8 & 0.1 & 57 & 2.5 & \\
\hline \multicolumn{6}{|c|}{ Pre-pregnancy BMI, kg/m² } \\
\hline$<20$ & 124 & 1.6 & 36 & 1.6 & \multirow[t]{5}{*}{0.44} \\
\hline $20-24.9$ & 516 & 6.8 & 213 & 9.3 & \\
\hline $25-29.9$ & 424 & 5.6 & 157 & 6.9 & \\
\hline $30+$ & 334 & 4.5 & 115 & 5.0 & \\
\hline Not stated & 6134 & 81.3 & 1769 & 77.2 & \\
\hline \multicolumn{6}{|l|}{ Parity } \\
\hline Primiparous & 2773 & 36.8 & 1460 & 63.8 & \multirow[t]{2}{*}{$<0.01$} \\
\hline Multiparous & 4768 & 63.2 & 830 & 36.2 & \\
\hline \multicolumn{6}{|c|}{ Smoking during pregnancy } \\
\hline Smoked & 1023 & 13.6 & 47 & 2.1 & \multirow[t]{3}{*}{$<0.01$} \\
\hline Did not smoke & 4533 & 60.1 & 1709 & 74.6 & \\
\hline Not stated & 1985 & 26.3 & 534 & 23.3 & \\
\hline \multicolumn{6}{|c|}{ Indigenous status of mothers } \\
\hline Non-Indigenous & 7239 & 96.0 & 2280 & 99.6 & \multirow[t]{3}{*}{$<0.01$} \\
\hline Indigenous & 295 & 3.9 & 9 & 0.4 & \\
\hline Not stated & 7 & 0.1 & 1 & 0.0 & \\
\hline \multicolumn{6}{|c|}{ Admitted patient elected accommodation status } \\
\hline Public & 5014 & 66.5 & 612 & 26.7 & \multirow[t]{3}{*}{$<0.01$} \\
\hline Private & 2519 & 33.4 & 1676 & 73.2 & \\
\hline Not stated & 8 & 0.1 & 2 & 0.1 & \\
\hline \multicolumn{6}{|c|}{ Pre-existing hypertension } \\
\hline Yes & 82 & 1.1 & 34 & 1.5 & \multirow[t]{3}{*}{0.13} \\
\hline No & 7394 & 98.1 & 2242 & 97.9 & \\
\hline Not stated & 65 & 0.9 & 14 & 0.6 & \\
\hline \multicolumn{6}{|l|}{ Pre-existing diabetes } \\
\hline Yes & 42 & 0.6 & 13 & 0.6 & \multirow[t]{3}{*}{0.96} \\
\hline No & 7431 & 98.5 & 2262 & 98.8 & \\
\hline Not stated & 68 & 0.9 & 15 & 0.7 & \\
\hline \multicolumn{6}{|c|}{ Antepartum haemorrhage } \\
\hline Yes & 340 & 4.5 & 130 & 5.7 & \multirow[t]{2}{*}{0.02} \\
\hline No & 7201 & 95.5 & 2160 & 94.3 & \\
\hline \multicolumn{6}{|c|}{ Pregnancy-induced hypertension } \\
\hline Yes & 634 & 8.4 & 280 & 12.2 & \multirow[t]{2}{*}{$<0.01$} \\
\hline No & 6907 & 91.6 & 2010 & 87.8 & \\
\hline
\end{tabular}


Table 1 Demographics, pre-existing conditions and pregnancy complications of mothers of ART and non-ART twin sets, Australia, 2007-2011 (Continued)

\begin{tabular}{|c|c|c|c|c|c|}
\hline & \multicolumn{2}{|c|}{ Non-ART mothers $(n=7541)$} & \multicolumn{2}{|c|}{ ART mothers $(n=2290)$} & \multirow{2}{*}{$\begin{array}{l}P \text { value (chi- } \\
\text { squared test) }\end{array}$} \\
\hline & No. & $\%$ & No. & $\%$ & \\
\hline \multicolumn{6}{|c|}{ Gestational diabetes } \\
\hline Yes & 567 & 7.5 & 222 & 9.7 & \multirow[t]{2}{*}{$<0.01$} \\
\hline No & 6974 & 92.5 & 2068 & 90.3 & \\
\hline
\end{tabular}

"independent samples t-test

twins. After adjusted for maternal characteristics, liveborn ART twins had $28 \%$ increased odds of having any adverse neonatal outcome (AOR 1.28 95\% CI 1.09-1.50) compared to non-ART liveborn twins. The sensitivity analysis by excluding BMI and smoking during pregnancy shows liveborn ART twins had 25\% increased odds of having any adverse neonatal outcome (AOR 1.25 95\% CI 1.07-1.47) (Table 4).

Of liveborn twins where sex is available for both babies, same-sex ART twins had higher odds of preterm birth (AOR 1.19; 95\% CI 1.08-1.31) and requiring resuscitation (AOR 1.28; 95\% CI 1.16-1.41). The rate of any adverse neonatal outcome was slightly higher in same-sex ART twins than non-ART twins, but not statistically significant (AOR 1.20 95\% CI 0.97-1.49).

For opposite-sex liveborn twins, ART twins had higher odds of Apgar score at $5 \mathrm{~min}<7$ (AOR 1.53 95\% CI 1.08-2.17), preterm birth (AOR 1.37 95\% CI 1.20-1.55), low birthweight (AOR 1.34 95\% CI 1.181.52), requiring resuscitation (AOR 1.25 95\% CI 1.11-

Table 2 Birth outcomes of ART and non-ART twins, Australia, 2007-2011

\begin{tabular}{|c|c|c|c|c|c|}
\hline & \multicolumn{2}{|c|}{$\begin{array}{l}\text { Non-ART twins } \\
(N=15,082)\end{array}$} & \multicolumn{2}{|c|}{$\begin{array}{l}\text { ART twins } \\
(N=4580)\end{array}$} & \multirow[t]{2}{*}{$\begin{array}{l}P \text {-value (chi- } \\
\text { squared test) }\end{array}$} \\
\hline & No. & $\%$ & No. & $\%$ & \\
\hline \multicolumn{6}{|l|}{ Delivery method } \\
\hline Vaginal & 4587 & 30.4 & 758 & 16.6 & $<0.01$ \\
\hline $\begin{array}{l}\text { Labour caesarean } \\
\text { section }\end{array}$ & 3104 & 20.6 & 1011 & 22.1 & \\
\hline $\begin{array}{l}\text { No labour caesarean } \\
\text { section }\end{array}$ & 7038 & 46.7 & 2764 & 60.3 & \\
\hline Not stated & 353 & 2.3 & 47 & 1.0 & \\
\hline \multicolumn{6}{|l|}{ Birth status } \\
\hline Live birth & 14,734 & 97.7 & 4516 & 98.6 & $<0.01$ \\
\hline Stillbirth (fetal death) & 348 & 2.3 & 64 & 1.4 & \\
\hline \multicolumn{6}{|l|}{ Preterm birth } \\
\hline Yes & 8585 & 56.9 & 2818 & 61.5 & \\
\hline - Spontaneous & 4050 & 26.8 & 1104 & 24.1 & $<0.01$ \\
\hline $\begin{array}{l}\text { - Induced or no } \\
\text { labor CS }\end{array}$ & 4535 & 30.1 & 1714 & 37.4 & \\
\hline No & 6497 & 43.1 & 1762 & 38.5 & \\
\hline
\end{tabular}

1.42), and NICU/SCN admission (AOR 1.28 95\% CI 1.13-1.46). Overall, opposite-sex liveborn ART twins had a $42 \%$ increased risk of having any adverse neonatal outcome compared to non-ART twins (AOR 1.42 95\% CI 1.11-1.82).

\section{Discussion}

The current analysis showed that ART twins had significantly higher rates of adverse neonatal outcomes in terms of preterm birth, low birthweight, the need for resuscitation and admission to NICU/SCN, long hospital stay and birth by caesarean section. In addition, among liveborn twins, ART twins had 28\% increased odds of having any adverse neonatal outcome (AOR 1.28, 95\% CI 1.09-1.50), especially for opposite-sex ART twins (AOR 1.42, 95\% CI 1.11-1.82).

We found that ART mothers had higher rates of antepartum haemorrhage, pregnancy-induced hypertension, and gestational diabetes compared with non-ART mothers. This is consistent with results from two other studies [4, 9]. These adverse outcomes are partially explained by the background of subfertility or infertility. Women experiencing infertility, whether or not they undertake ART, have higher rates of many adverse outcomes when compared to women conceiving spontaneously within 12 months of trying [13].

Table 3 Monozygotic and dizygotic ART and non-ART twins, Australia, 2007-2011

\begin{tabular}{|c|c|c|c|c|}
\hline & \multicolumn{2}{|c|}{ Non-ART } & \multicolumn{2}{|l|}{ ART } \\
\hline & No. & $\%$ & No. & $\%$ \\
\hline Opposite-sex twins & 4300 & 28.6 & 2048 & 44.8 \\
\hline Same-sex twins & 10,756 & 71.4 & 2526 & 55.2 \\
\hline \multicolumn{5}{|c|}{ Weinberg's differential rule } \\
\hline Dizygotic twins & 8600 & & 4096 & \\
\hline Monozygotic twins & 6456 & & 478 & \\
\hline $\begin{array}{l}\text { All births where sex } \\
\text { is available }\end{array}$ & 582,475 & & 24,071 & \\
\hline $\begin{array}{l}\text { Twins where sex is } \\
\text { available }\end{array}$ & 15,056 & & 4574 & \\
\hline Dizygotic twin rate & & 1.5 & & 17.0 \\
\hline Monozygotic rate & & 1.1 & & 2.0 \\
\hline
\end{tabular}


Table 4 Neonatal outcomes of liveborn ART and non-ART twins, Australia, 2007-2011

\begin{tabular}{|c|c|c|c|c|c|c|}
\hline & Total & No. & $\%$ & OR $(95 \% \mathrm{Cl})$ & $\operatorname{AOR}^{a}(95 \% C l)$ & $\mathrm{AOR}^{\mathrm{b}}(95 \% \mathrm{Cl})$ \\
\hline \multicolumn{7}{|c|}{ Apgar score at $5 \min <7$} \\
\hline Non-ART & 14,718 & 556 & 3.8 & 1.00 & & \\
\hline ART & 4506 & 169 & 3.8 & $0.99(0.83-1.18)$ & $1.24(1.02-1.52)$ & $1.22(1.01-1.50)$ \\
\hline \multicolumn{7}{|l|}{ Preterm } \\
\hline Non-ART & 14,734 & 8281 & 56.2 & 1.00 & 1.00 & \\
\hline ART & 4516 & 2764 & 61.2 & $1.23(1.15-1.32)$ & $1.13(1.05-1.22)$ & $1.13(1.05-1.22)$ \\
\hline \multicolumn{7}{|c|}{ Low birth weight } \\
\hline Non-ART & 14,728 & 7415 & 50.3 & 1.00 & 1.00 & \\
\hline ART & 4515 & 2474 & 54.8 & $1.20(1.12-1.28)$ & $1.13(1.05-1.22)$ & $1.11(1.03-1.20)$ \\
\hline \multicolumn{7}{|l|}{ Resuscitation } \\
\hline Non-ART & 14,727 & 7038 & 47.8 & 1.00 & 1.00 & \\
\hline ART & 4514 & 2569 & 56.9 & $1.44(1.35-1.54)$ & $1.26(1.17-1.36)$ & $1.29(1.20-1.39)$ \\
\hline \multicolumn{7}{|c|}{ Admission to intensive or special care nursery } \\
\hline Non-ART & 14,355 & 8626 & 60.1 & 1.00 & 1.00 & \\
\hline ART & 4445 & 2945 & 66.3 & $1.30(1.22-1.40)$ & $1.08(1.00-1.17)$ & $1.09(1.01-1.18)$ \\
\hline \multicolumn{7}{|c|}{ Length of infant stay $\geq 5$ days in hospital } \\
\hline Non-ART & 14,733 & 10,084 & 68.4 & 1.00 & 1.00 & \\
\hline ART & 4516 & 3683 & 81.6 & $2.04(1.88-2.21)$ & $1.06(0.97-1.17)$ & $1.04(0.95-1.14)$ \\
\hline \multicolumn{7}{|c|}{ Neonatal death } \\
\hline Non-ART & 14,734 & 262 & 1.8 & 1.00 & 1.00 & \\
\hline ART & 4516 & 93 & 2.1 & $1.16(0.92-1.48)$ & $1.32(1.01-1.73)$ & $1.31(1.01-1.72)$ \\
\hline \multicolumn{7}{|c|}{ Any adverse outcome } \\
\hline Non-ART & 14,734 & 13,106 & 89.0 & 1.00 & 1.00 & \\
\hline ART & 4516 & 4304 & 95.3 & $2.52(2.18-2.92)$ & $1.28(1.09-1.50)$ & $1.25(1.07-1.47)$ \\
\hline
\end{tabular}

adjusted for maternal age, parity, Indigenous status of mother, pre-pregnancy BMI, and smoking during pregnancy

badjusted for maternal age, parity, and Indigenous status of mother

In agreement with other studies, we found that the rate of preterm birth is significantly higher among ART twins than non-ART twins [9]. There are a number of potential explanations for the increased risk of preterm birth in ART births including the underlying maternal characteristics such as subfertility or medical conditions causing subfertility, obesity, and short stature, and the ART treatment itself [14]. The increased risk of preterm birth among twins is also partially explained by early fetal loss in a higher order multiple pregnancy [15]. Pinborg and colleagues suggested that survivors of a vanishing fetal hearts/gestational sacs were more likely to be born preterm and with low birth weight [15].

Our results illustrated that the rate of low birthweight in ART twins is significantly higher than non-ART twins. This is consistent with findings in a previous systematic review which reported a $14 \%$ increase in the risk of low birthweight among ART twins compared to non-ART twins (RR 1.14, 95\% CI 1.06-1.22) [16]. The increased risk of low birthweight births in ART twins can partially be explained by the higher preterm birth rate among ART twins compared with non-ART twins. However, in this study, as in previous reports, the higher rate of preterm birth alone does not explain the increased risk of low birthweight [16, 17]. Multiple pregnancies observed on the initial ultrasound is closely linked to the increased risk of low birthweight [18].

During the study period, the twin delivery rates following ART decreased from $24.5 \%$ in 2007 to $18.2 \%$ in 2011 . This has paralleled the increase in the proportion of single embryo transfer in Australia from $63.7 \%$ in 2007 to $73.2 \%$ in 2011 [6]. An Australian study suggested that a voluntary policy of single embryo transfer introduced in 2002 had a significant impact to the fall in the proportion of ART multiple births [19]. Other studies further advocated that continuing the policy of single embryo transfer would prevent multiple pregnancies and improve overall maternal and neonatal outcomes following ART [20, 21]. Luke 2017 concluded that transferring high quality and fewer embryos is responsible for reducing the risk of multiple births from ART treatments and ultimately reducing the perinatal adverse outcomes [22]. 
Our findings show that for opposite-sex twins, ART twins had $42 \%$ increase in the likelihood of any adverse neonatal outcome compared to non-ART twins. Opposite-sex twins are all dizygotic twins which arise from the fertilisation of two separate ova by two separate sperm resulting in the formation of two separate zygotes in natural pregnancy, or from multiple embryo transfers in ART pregnancy. Virtually all dizygotic twins develop their own placenta and membranes so are dizygotic dichorionic diamniotic twins. Exceptional cases of monochorionic dizygotic twins have been reported, however, they are very rare [23]. The higher rate of any adverse outcome in ART twins is possibly related to the underlying infertility of the couples, the development of the embryo in the laboratory or the transfers of multiple embryos [24].

Interestingly, we found that the rate of any adverse neonatal outcome was higher among same-sex ART twins than same-sex non-ART twins, but it was not statistically significant. Same sex twins can be monozygotic or dizygotic twins, given that all monozygotic twins are same-sex twins and about half of dizygotic twins are of the same sex [23]. In natural pregnancy, monozygotic twins develop by splitting zygote from the fertilisation of a single ovum with a single sperm [25]. Subsequent placentation depends on the time of zygote splitting, with monozygotic dichorionic twins if splitting before day 3 and monozygotic monochorionic twins if splitting on day 3 or after. In ART pregnancy, monozygotic twins result from the splitting of the single transferred embryo. Since embryo transfers are virtually all on day 3 or after, monozygotic monochorionic twins are likely to develop [26]. However, we are unable to identify monozygotic twins from same-sex dizygotic twins and compare the neonatal outcomes between ART monozygotic twins and non-ART monozygotic twins.

Without genetic testing and details of the number of embryos transferred available, it is difficult to identify monozygotic twins. One way to estimate the rate of monozygotic twins is to use the sex of twin pairs by applying Weinberg's differential rule [26]. Our data showed that the proportion of same-sex twins was lower among ART group (55.2\%) than non-ART group (71.4\%). This proportion is slightly higher than Pinborg and colleagues proportions of same-sex twins (50.8\% among ART twins and $65.3 \%$ among non-ART twins) [27] but, similar to the Australian register [28]. Based on Weinberg's differential rule, we estimated that among ART births, monozygotic twin rate was 2.0 and $1.1 \%$ among non-ART births. These estimates are higher than the monozygotic twin rates from a systematic review where the rate was 0.9\% (95\% CI: $0.8-0.9 \%$ ) in ART twins compared to $0.4 \%$ (95\% CI: 0.4-0.4) in naturally conceived twins [29].

The major strength of this study was the population based-design. The advantage of population-based studies rests on the inclusion of all patients in a given population and are therefore have less tendency to selection biases compared to the other types of observational studies [30].

Twin pregnancies following ART treatment are highly associated with multiple embryo transfers [31]. Unfortunately, the number of embryos transferred is not captured in the NPDC. We were unable to further investigate the ART twins by single or multiple embryo transfers. In addition, there were other limitations in this study. Apart from number of embryos transferred, other detailed type of ART treatment and procedures were not available in NPDC, such as fresh versus frozen embryo transfer, cleavage versus blastocyst transfers. Studies have demonstrated that the perinatal outcomes vary by fresh versus frozen embryo transfers, autologous versus donor treatment and cleavage versus blastocyst transfers $[20,21,32]$. The information on BMI and smoking during pregnancy was not stated for a large proportion of mothers $(80.4 \%$ for BMI and $25.6 \%$ for smoking during pregnancy). This reflected that some jurisdictions did not have smoking status and or BMI in their routine data collection. The large proportion of mothers with missing data on BMI and smoking during pregnancy and the differential missing data between ART and non-ART mothers would have reduced the validity of the comparison and multivariate analysis.

\section{Conclusion}

This study using population cohort approach provided a high level of evidence where a randomized controlled trial is not feasible. The findings of this study strengthen the evidence on of higher adverse neonatal outcomes among ART twins than non-ART twins. These adverse outcomes are likely related to both the type of conception and the underlying infertility of the women. Women/couples accessing ART treatment should be fully informed of the risk of adverse outcome of twin pregnancies following ART treatment.

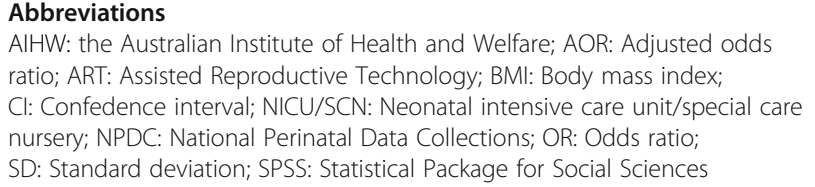

\section{Acknowledgements}

This research is based on data made available by AlHW. The authors acknowledge AlHW for funding the NPDC and midwives and neonatal nurses for collecting data for the NPDC

\section{Availability of data and materials}

The data that support the findings of this study are available from the Australian Institute of Health and Welfare (AlHW) but restrictions apply to the availability of these data, which were used under license for the current study, and so are not publicly available. Data are however available from the authors upon reasonable request and with permission of AlHW. 


\section{Authors' contributions}

All authors have contributed to the conducting of this study. AW designed the study, prepared the data, drafted the manuscript, and approved the final manuscript as submitted. NS and FA carried out the initial analyses, drafted the manuscript and approved the final manuscript as submitted. KL, ZL and $\mathrm{MU}$ reviewed and revised the manuscript, and approved the final manuscript as submitted. ES conceptualised and designated the study, reviewed and revised the manuscript, and approved the final manuscript as submitted.

\section{Ethics approval and consent to participate}

Ethics approval for this study was granted by the Human Research Ethics Committee of the University of New South Wales (HREC 11024) and the Australian Institute of Health and Welfare Ethics Committee (EC 2011/1/5). The dataset supporting the conclusion was pre-collected in non-identifiable format. Therefore, informed consent was waived by the ethics committee.

\section{Consent for publication}

Not applicable.

\section{Competing interests}

Alex Wang is a member of the editorial board (Associate Editor) of BMC Pregnancy and Childbirth.

\section{Publisher's Note}

Springer Nature remains neutral with regard to jurisdictional claims in published maps and institutional affiliations.

\section{Author details}

${ }^{1}$ Faculty of Health, Australian Centre of Public and Population Health Research, University of Technology Sydney, PO Box 123 Broadway, Ultimo, NSW 2007, Australia. 'School of Women's and Children's Health, the University of New South Wales, Sydney, NSW 2052, Australia. ${ }^{3}$ Department of Obstetrics and Gynaecology, Royal Women's Hospital, University of Melbourne, Parkville, VIC 3052, Australia.

\section{Received: 13 February 2018 Accepted: 26 July 2018}

Published online: 08 August 2018

\section{References}

1. Martin JA, Hamilton BE, Osterman MJ. Three decades of twin births in the United States. NCHS data brief. 1980-2009;2012(80):1-8.

2. Hilder L, Zhichao Z, Parker M, Jahan S, Chambers G. Australia's mothers and babies 2012. Perinatal statistics series no. 30. Cat. no. PER 69. In: Perinatal statistics series no. 30. Cat. no. PER 69. Canberra: Australian Institute of Health and Welfare; 2014

3. Lancaster P, Pedisich EL, Huang J. Australia's Mothers and Babies 1992. In: Perinatal Statistics Series no. 2. National Perinatal Statistics Unit. Canberra: Australian Institute of Health and Welfare; 1995.

4. Domingues AP, Dinis SR, Belo A, Couto D, Fonseca E, Moura P. Impact of induced pregnancies in the obstetrical outcome of twin pregnancies. Fertil Steril. 2014;101(1):172-7.

5. Sunderam S, Kissin DM, Crawford SB, Folger SG, Jamieson DJ, Barfield WD. Assisted reproductive technology surveillance-United States, 2011. MMWR Surveil Summ. 2014;63(SS-10):1-28.

6. Macaldowie A, Lee E, Chambers GM. Assisted reproductive technology in Australia and New Zealand 2013. Sydney: National Perinatal Epidemiology and Stastistics Unit, The University of New South Wales; 2015.

7. Geisler ME, O'Mahony A, Meaney S, Waterstone JJ, O'Donoghue K. Obstetric and perinatal outcomes of twin pregnancies conceived following IVF/ICSI treatment compared with spontaneously conceived twin pregnancies. Eur J Obstet Gynecol Reprod Biol 2014, 181(0):78-83.

8. Fan C, Sun Y, Yang J, Ye J, Wang S. Maternal and neonatal outcomes in dichorionic twin pregnancies following IVF treatment. A hospital-based comparative study. Int J Clin Exp Pathol. 2013;6(10):2199-207.

9. Adler-Levy $Y$, Lunenfeld $E$, Levy A. Obstetric outcome of twin pregnancies conceived by in?vitro fertilization and ovulation induction compared with those conceived spontaneously. Eur J Obstet Gynecol Reprod Biol. 2007; 133(2):173-8.

10. Li Z, Zeki R, Hilder L, Sullivan E. Australia's mothers and babies 2011 , perinatal statistics series no. 28. Cat. no. PER 59. Canberra: Australian Institute of Health and Welfare; 2013.
11. Wang YA, Chughtai AA, Farquhar CM, Pollock W, Lui K, Sullivan EA. Increased incidence of gestational hypertension and preeclampsia after assisted reproductive technology treatment. Fertil Steril 2016;105(4):920-926 e922.

12. Fellman J. Statistical analyses of monozygotic and dizygotic twinning rates. Twin Res Hum Genet. 2013;16(6):1107-11.

13. Healy DL, Breheny S, Halliday J, Jaques A, Rushford D, Garrett C, Talbot JM, Baker HW. Prevalence and risk factors for obstetric haemorrhage in 6730 singleton births after assisted reproductive technology in Victoria Australia. Hum Reprod. 2010;25(1):265-74.

14. Dickey RP, Xiong X, Xie Y, Gee RE, Pridjian G. Effect of maternal height and weight on risk for preterm singleton and twin births resulting from IVF in the United States, 2008-2010. Am J Obstet Gynecol. 2013;209(4:349):e341-6.

15. Pinborg A, Lidegaard O, la Cour FN, Andersen AN. Consequences of vanishing twins in IVF/ICSI pregnancies. Hum Reprod. 2005;20(10):2821-9.

16. McDonald SD, Han Z, Mulla S, Ohlsson A, Beyene J, Murphy KE. Preterm birth and low birth weight among in?vitro fertilization twins. A systematic review and meta-analyses. Eur J Obstet Gynecol Reprod Biol. 2010;148(2):105-13.

17. Nelson SM, Lawlor DA. Predicting live birth, preterm delivery, and low birth weight in infants born from in?vitro fertilisation: a prospective study of 144,018 treatment cycles. PLoS Med. 2011;8(1):e1000386.

18. Schieve LA, Meikle SF, Ferre C, Peterson HB, Jeng G, Wilcox LS. Low and very low birth weight in infants conceived with use of assisted reproductive technology. N Engl J Med. 2002;346(10):731-7.

19. Umstad MP, Hale L, Wang YA, Sullivan EA. Multiple deliveries: the reduced impact of in?vitro fertilisation in Australia. Aust N Z J Obstet Gynaecol. 2013; 53(2):158-64.

20. Sullivan EA, Wang YA, Hayward I, Chambers GM, Illingworth P, McBain J, Norman RJ. Single embryo transfer reduces the risk of perinatal mortality, a population study. Hum Reprod. 2012;27(12):3609-15.

21. Wang YA, Sullivan EA, Healy DL, Black DA. Perinatal outcomes after assisted reproductive technology treatment in Australia and New Zealand: single versus double embryo transfer. Med J Aust. 2009:190(5):234-7.

22. Luke B. Pregnancy and birth outcomes in couples with infertility with and without assisted reproductive technology: with an emphasis on US population-based studies. Am J Obstet Gynecol. 2017;217(3):270-81.

23. Umstad MP, Short RV, Wilson M, Craig JM. Chimaeric twins: why monochorionicity does not guarantee monozygosity. Aust N Z J Obstet Gynaecol. 2012;52(3):305-7.

24. Declercq E, Luke B, Belanoff C, Cabral H, Diop H, Gopal D, Hoang L, Kotelchuck M, Stern JE, Hornstein MD. Perinatal outcomes associated with assisted reproductive technology: the Massachusetts outcomes study of assisted reproductive technologies (MOSART). Fertil Steril. 2015;103(4):888-95.

25. Aston $\mathrm{Kl}$, Peterson CM, Carrell DT. Monozygotic twinning associated with assisted reproductive technologies: a review. Reproduction. 2008;136(4):377-86.

26. Blickstein I. Estimation of iatrogenic monozygotic twinning rate following assisted reproduction: pitfalls and caveats. Am J Obstet Gynecol. 2005 192(2):365-8.

27. Pinborg A, Loft A, Schmidt L, Greisen G, Rasmussen S, Andersen AN Neurological sequelae in twins born after assisted conception: controlled national cohort study. BMJ. 2004;329(7461):311.

28. Hopper JL, Foley DL, White PA, Pollaers V. Australian twin registry: 30 years of progress. Twin Res Hum Genet. 2013;16(1):34-42.

29. Vitthala S, Gelbaya TA, Brison DR, Fitzgerald CT, Nardo LG. The risk of monozygotic twins after assisted reproductive technology: a systematic review and meta-analysis. Hum Reprod Update. 2009;15(1):45-55.

30. Booth CM, Tannock IF. Randomised controlled trials and population-based observational research: partners in the evolution of medical evidence. $\mathrm{Br} J$ Cancer. 2014:110(3):551-5.

31. Fauser BC, Devroey $P$, Macklon NS. Multiple birth resulting from ovarian stimulation for subfertility treatment. Lancet. 2005;365(9473):1807-16.

32. Li Z, Wang YA, Ledger W, Edgar DH, Sullivan EA. Clinical outcomes following cryopreservation of blastocysts by vitrification or slow freezing: a population-based cohort study. Hum Reprod. 2014;29(12):2794-801. 